\title{
Influencing Factors in Using Interactive E-Learning Tool
}

\author{
Au Thien Wan \\ School of Computing and Informatics, Universiti Teknologi Brunei, Tungku Highway, Brunei Darussalam \\ Email: twan.au@utb.edu.bn
}

Received 9 December 2015; accepted 22 February 2016; published 29 February 2016

\begin{abstract}
We are investigating the factors that could have effect on the learning outcomes of an interactive eLearning tool. Our experiment consisted of participants from undergraduate and postgraduate students spanning across three semesters in a Database Management System course conducted in a blended learning environment. The eLearning tool has a built in data event logger whenever a student used the system to capture the interaction. We analyze the learning outcomes and effectiveness through the captured interactive events with factors such as the students' course perceptions (CP), evaluation of self-efficacy (SE) beliefs, class attendance, student gender, and academic discipline based on social learning theory. We used analytical path model, $t$-test and one-way $A N O V A$ to determine the influencing factors directly related to the interactive eLearning tool.
\end{abstract}

\section{Keywords}

E-Learning, Social Learning Theory, Self-Efficacy, Course Perception, Analytical Path Model

\section{Introduction}

This study investigates the learning outcomes of an interactive eLearning tool on the learners and the factors that may have caused the effects. It was conducted with participants over 400 Higher Learning Institution (HLI) students spanning across three semesters in a Database Management Systems course conducted in a blended learning environment. Interaction with the eLearning system was collected and a survey was conducted at the end of each semester for more data collection. This study of learning effectiveness is based on social learning theory and used a number of influencing factors such as the students' course perceptions (CP) and evaluation of self-efficacy (SE) beliefs, tutorial attendance, student gender, and academic discipline. We use the analytical path model, t-test and one-way ANOVA to analyse the data sets. The analysis reveals consistent usage and a higher level of eLearning engagement for above average performance students. These patterns of usage provide key indicators for learning effectiveness. Our results also show that SE, tutorial attendance, and academic discipline are mediating factors and have a direct impact on learning effectiveness.

In the next section we will discuss the related work with the hypothesis and the proposed model. We will then discuss the methodology followed by the result and discussion. This will be followed by a conclusion at the end. 


\section{Related Work}

Various factors in learning environments and in the student themselves affect the way they go about the process of learning. There are studies conducted online, in conventional education, and in organisations that provide concrete evidence and frameworks for the effectiveness and the factors that contribute to learning and learning transfer. Very little is being investigated on the factors behind the effectiveness of the interactive eLearning tool in a blended learning environment.

In Vermunt's [1] work, for example, he looked into the relationship between the learners' ways of learning and personal, contextual and performance variables in education in general. In the study, a comprehensive and detailed analysis was conducted on whether and how age, gender, academic disciplines, and performance outcomes affect students' learning patterns in a middle size university.

From an organisational training perspective on factors affecting learning transfer or learning effectiveness, Baldwin and Ford [2] provided a critique of the existing transfer research and suggested directions for future research. The review also noted key limitations relevant to the way transfer had been operationalized. They closed their review by noting that the existing researches are problematic, given the relatively short-term, single source, perceptual database that has been created. Since then, the transfer literature has expanded to address a number of issues raised in that review [3]. A wider array of individual differences and motivational variables has been studied for their impact on learning effectiveness. In addition, a number of studies have examined the learning environment for its impact on the transfer of learning.

Recent attempts were made to qualitatively summarize what we know about learning effectiveness from this expanding research base [4]-[8]. These reviews have typically focused on trainee and work environment characteristics and their impact on transfer; moreover, they highlight several inconsistent and conflicting findings in the literature. For instance, [7] conclude in their findings that the relationships between general dispositions and learning transfer have shown incoherent results. Similarly, [6] concluded that there was mixed support for conscientiousness and that other personality variables were said to have minimal or no empirical evidence supporting their relationship with learning transfer. They also described the mixed findings for the impact of trainee interventions on learning effectiveness.

\section{Hypothesis}

E-Learning interactive engagement represents the interaction and learners' experiences between learners and an interactive eLearning tool called Database Learning Tool (DBLT). DBLT is a 24/7 online eLearning tool to supplement students' learning in an introductory course on Database Management Systems. Students can login to DBLT at their own initiative and work through the examples to enhance their conventional learning [9]. The DBLT recorded a count when a student responds to a question. In our system the count to question responses is more meaningful than the time spent using the DBLT. A student could log on to DBLT for a long time doing unrelated things and only spend minimally related to their learning. Therefore in our study the count of responses is used as the variable for eLearning interaction. Hence the more counts a student makes, the greater the experience as well as the amount of learning. We believe that the interaction with the eLearning tool have a direct impact on student's learning outcomes in terms of GPA performance and hence the following hypothesis:

H1: Students' eLearning interactive engagement is direct function to their academic performance (GPA).

When interacting with an eLearning tool, an individual can acquire attitude, readjust behaviour, and gain knowledge. Individual learning process through an eLearning tool is also composed of: 1) SE beliefs; and 2) satisfaction or the learners' perception (CP) of a course, in a blended learning environment. Based in grounded social cognitive theory [10], self-efficacy (SE) has been a research focus as a predictor of individual perception and computer technology use. ELearning provides an alternative channel to learn at any point in time and space, and provides more opportunities to be an active self-regulated learner. Bandura's social learning theory [11] [12] also stresses the self-regulation of learning that functions as an initial motive for achieving desirable learning outcomes. Accordingly, individuals will self-initiate, regulate their learning, and actively construct knowledge by acquiring, generating, and structuring information. This results in learning activities that centre on learner autonomy and interactive learning actions. ELearning offers more opportunities for improving problem solving capabilities and achieving learning effectiveness [13].

The attitude of the learners are also key to individuals attaining desirable learning outcomes which is reflected through reactions or the learners' perception of the course in terms of their satisfaction towards the learning. The 
study [14] indicated that the level of learners' satisfaction was significantly in terms of the level of transfer of learning. Based on the argument above, we hypothesize that:

H2: Students' eLearning interactive is a function to their SE beliefs,

H3: Students' eLearning interactive is related to CP and,

H4: Students' CP is directly related to performance outcome (GPA).

Bandura [10] defines SE as personal beliefs about one's capabilities to learn or perform skills at designated levels. Individuals' SE beliefs influence their thoughts, emotional reactions, and behavior. People with high SE beliefs are more persistence, less fear, willing to solve problem, and therefore feel more confident in enabling the achievement of level of outcomes [10]. Thus we hypothesize that:

H5: Students' SE belief is related to the transfer of learning.

We therefore propose the research model shown in Figure 1 by using an analytical path model, based on our argument above.

\section{Methodology}

The experiment was carried out over three semesters with more than400students from diverse backgrounds. The course ran normally with 1 lecture, 1 lab session and 1 tutorial session. The assessment consist of two class tests, one assignment and a final exam at the end of the semester. The students' interactions with the DBLT were recorded throughout. We recorded that only 354 used the DBLT. There were 150 respondents to the survey questionnaires and, of these, five were eliminated due to incompleteness. Of the remaining 145 usable responses, 59 are female and 86 male.

We used analytical path model to measure the effect of eLearning interaction and experience on the performance outcomes. Three major instruments proposed by Kraiger et al. [15]: cognitive (directly from GPA-based performance); affective (self-efficacy belief and perception of course); and skill-based (directly from GPA based performance) were measured using the data collected through DBLT logs and the feedback from survey questionnaires from students. The DBLT logs collected form the basis of the data for eLearning interaction and the survey data form the learners' reaction and self-efficacy. The GPA performance the students achieved at the end of semester was used to measure the knowledge and skill based learning domain. Students' attendance, gender and academic disciplines information were collected directly.

Survey questions used 5-point Likert scale to measure the variables of SE and CP of students. SE and CP questionnaires were based on Bandura's SE theory [11] and Kirkpatrick's theory on training evaluation [16] where 11 items were related to SE belief and 12 items related to students' CP. The GPA aggregation is from two inter-semester tests, one assignment, and a final exam.

\section{Results and Discussion}

Partial Least Squares (PLS) was used to analyse the survey and collected data for the hypotheses H. T-test, one-way ANOVA, and the Pearson correlation tested the factors for the gender, academic disciplines, and attendance respectively to check the influence on the GPA outcomes.

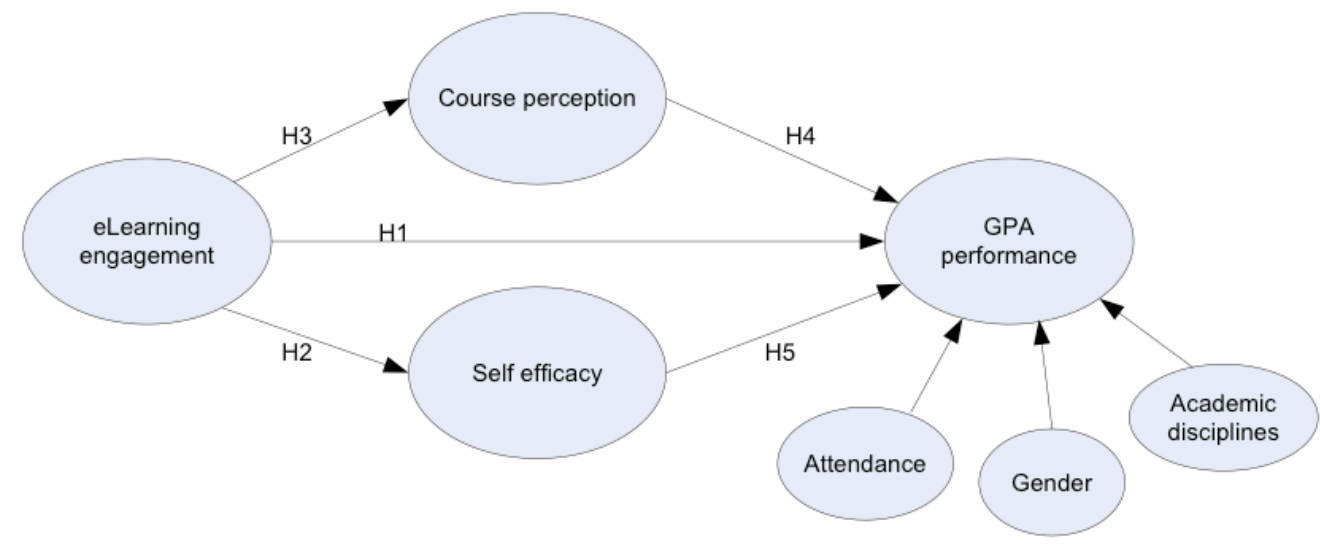

Figure 1. Relationship between various factors and GPA performance. 


\section{Descriptive statistics and correlations amongst the direct and endogenous factors}

SPSS was used for the statistics on normality assumption, the means, standard deviations, skewness and Kurtois. The absolute values of skewness ranged from 0.75 to 0.99 , while the absolute values of the Kurtois ranged from 0.26 to 1.08 , all of which did not exceed the absolute value of 2.0, indicating the normal distribution of data. Correlations were also examined to test the strength of the relationships amongst the interested variables. The results revealed correlation amongst all of the variables at the alpha level of 0.01 (Table 1).

\section{Assessment of measurement model and hypothesis testing}

Reliability and validity of the variables CP and SE was based on guidelines set out by Joreskog and Sorbom [17]. The values for Cronbach's coefficient $(\alpha)$ were all above 0.7 indicating a reliability measurement instrument. We assessed convergent validity by examining composite reliability (CR) and average variance (AVE) extracted from the constructs. CR values are higher than the suggested minimum of 0.7 and AVE values were all above 0.5, thus providing evidence of convergence validity. The Variance Inflation Factors (VIF) for the independent variables of CP and SE indicating no significant collinearity between the independent variables, confirming that factors do not load onto each other in the measurement [18].

Partial Least Square (PLS) was used to test the hypothesized relationship of eLearning interactive engagement, $\mathrm{CP}, \mathrm{SE}$ and tutorial attendance. It estimates the parameters of the structural model, that is, the strength and direction of the relationship among the model variables [19]. Table 2 shows the summary of the results. The models' predictive power was also assessed by measuring $\mathrm{R}^{2}$ for the variables for $\mathrm{H} 1, \mathrm{H} 4$ and $\mathrm{H} 5$.

The first hypothesis, H1, strongly suggests a positive impact of interactive eLearning on students' learning transfer and, hence, their GPA performance $(\beta=0.244)$. This result confirms that interactive eLearning leads students to improved performance.

Hypothesis H2 $(\beta=0.362)$ and $\mathrm{H} 3(\beta=0.472)$ confirm that learners satisfaction in course perception and achieve a better SE belief after using the interactive eLearning tool.

Hypothesis H4 ( $\beta=-0.119)$ does not support our argument that CP has a positive impact on the transfer of learning. We believe that $\mathrm{CP}$ and $\mathrm{SE}$ are strongly related in eLearning. Therefore a partial positive contribution from $\mathrm{CP}$ to the transfer of learning is not ruled out.

Our hypothesis H5 $(\beta=0.365)$ indicates that SE leads to academic success which is in line with [20]. Therefore SE has a positive impact on the transfer of learning.

\section{The effect of gender and academic background on GPA Performance}

As for the effect of gender, the $t$-test results found to have no significant effect on the learning outcomes between male and female students with $p=0.118$ which is greater than 0.05 assuming homogeneity of variance.

The academic discipline has an effect on the performance outcomes. We used one-way between groups ANOVA testing to confirm the results. Only students using the DBLT are tested and 349 students were available for the test. The result indicates that the significant value $(\mathrm{sig}=0.010)$ is less than 0.05 indicating that there is a significant difference somewhere among the mean scores for the different discipline backgrounds. Table 3 shows that the main significant values are only between IT and Engineering disciplines.

We ran the Pearson Correlation test on students attendance against the GPA performance outcomes and found that they are highly correlated (Table 1). We further ran PLS to test the $\beta$ path coefficient $(0.241)$ of the attendance and confirmed that it is significant $(p<0.05)$ in our study.

Table 1. Correlation of CP, SE and GPA to eLearning interaction.

\begin{tabular}{|c|c|c|c|c|c|c|c|}
\hline \multirow[b]{2}{*}{ Factors } & \multirow[b]{2}{*}{$M$} & \multirow[b]{2}{*}{$S D$} & \multicolumn{5}{|c|}{ Pearson correlation coefficient } \\
\hline & & & 1 & 2 & 3 & 4 & 5 \\
\hline eLearning interaction & 143.24 & 94.60 & 1 & - & - & - & - \\
\hline $\mathrm{CP}$ & 4.10 & 0.61 & $0.372^{* *}$ & 1 & - & - & - \\
\hline $\mathrm{SE}$ & 3.78 & 0.73 & $0.487^{* *}$ & $0.691^{* *}$ & 1 & - & - \\
\hline GPA grades & 5.51 & 1.41 & $0.491^{* *}$ & $0.531^{* *}$ & $0.570^{* *}$ & 1 & - \\
\hline Tutorial Attendance & 63.67 & 30.27 & $0.281^{* *}$ & $0.357^{* *}$ & $0.274^{* *}$ & $0.432^{* *}$ & 1 \\
\hline
\end{tabular}

\footnotetext{
${ }^{* *}$ Correlation is significant at the 0.01 level, Number of students $\mathrm{N}=145$.
} 
Table 2. Path coefficients $(\beta)$.

\begin{tabular}{cccc}
\hline Hypothesis & Factors & $\beta$ & Results \\
\hline H1 & Interaction & $0.244^{* *}$ & Supported \\
H2 & Interaction & $0.362^{* *}$ & Supported \\
H3 & Interaction & $0.472^{* *}$ & Supported \\
H4 & CP & -0.119 & Not Supported \\
H5 & SE & $0.365^{* *}$ & Supported \\
\hline
\end{tabular}

$\mathrm{R}^{2}$ for H1, H4, H5 and tutorial $=0.338,{ }^{* *}$ Indicate statistical significance at $p<0.01$.

Table 3. Comparisons of academic disciplines.

\begin{tabular}{|c|c|c|c|c|c|c|}
\hline \multirow{2}{*}{ (I) Discipline } & \multirow{2}{*}{ (J) Discipline } & \multirow{2}{*}{$\begin{array}{c}\text { Mean } \\
\text { Difference (I-J) }\end{array}$} & \multirow{2}{*}{ Std. Error } & \multirow{2}{*}{ Sig. } & \multicolumn{2}{|c|}{ 95\% Confidence Interval } \\
\hline & & & & & Lower Bound & Upper Bound \\
\hline \multirow{3}{*}{ B Eng } & Information Technology & $0.806^{*}$ & 0.222 & 0.002 & 0.232 & 1.380 \\
\hline & Arts and Business & 0.483 & 0.287 & 0.335 & -0.2586 & 1.224 \\
\hline & Science & 0.003 & 0.353 & 1.000 & -0.9076 & 0.913 \\
\hline \multirow{3}{*}{ Information Technology } & B Eng & $-0.806^{*}$ & 0.222 & 0.002 & -1.380 & -0.232 \\
\hline & Arts and Business & -0.323 & 0.239 & 0.531 & -0.940 & 0.294 \\
\hline & Science & -0.803 & 0.315 & 0.054 & -1.615 & 0.009 \\
\hline \multirow{3}{*}{ Arts and Business } & B Eng & -0.483 & 0.287 & 0.335 & -1.224 & 0.259 \\
\hline & Information Technology & 0.323 & 0.239 & 0.531 & -0.294 & 0.940 \\
\hline & Science & -0.480 & 0.363 & 0.550 & -1.418 & 0.458 \\
\hline \multirow{3}{*}{ Science } & B Eng & -0.003 & 0.353 & 1.000 & -0.913 & 0.908 \\
\hline & Information Technology & 0.803 & 0.315 & 0.054 & -0.009 & 1.615 \\
\hline & Arts and Business & 0.480 & 0.363 & 0.550 & -0.458 & 1.418 \\
\hline
\end{tabular}

*Statistically significant at $p<0.05$.

\section{Conclusions}

The purpose of the study is to investigate the factors influencing the learning effectiveness of interactive eLearning tools in a blended learning environment in HLI. We based our study on social learning theory and using an analytical path model to investigate the relationship between students' interaction and various direct and indirect factors. Our results found that eLearning interaction has a direct positive impact on the GPA performance outcomes of students. We found that students' eLearning interaction also has a positive relationship on the mediation effects of SE belief and learners' CP. The investigation showed a positive mediation effect of SE on the performance output. Although CP did not support the learning outcome in our investigation, we observed that it has some partial influence. The analysis indicates that attendance plays a positive role in the transfer of learning in a blended learning environment and gender has no effect to the learning outcomes. Academic disciplines have statistical significance impact to learning outcomes but only for IT and Engineering discipline.

This study serves as a good platform for continuous improvement for pedagogical practice from an educational point of view and provides recommendations for peer learners to improve learning outcomes from the student point of view.

\section{References}

[1] Vermunt, J.D. (2005) Relations between Student Learning Patterns and Personal and Contextual Factors and Academic 
Performance. Higher Education, 49, 205-234. http://dx.doi.org/10.1007/s10734-004-6664-2

[2] Baldwin, T.T., Ford, J.K., and Blume, B.D. (2005) Transfer of Training 1988-2008: An Updated Review and Agenda for Future Research. International Review of Industrial and Organizational Psychology, 24, 41-70.

[3] Ford, J.K. and Weissbein, D.A. (1997) Transfer of Training: An Updated Review and Analysis. Performance Improvement Quarterly, 10. http://dx.doi.org/10.1111/j.1937-8327.1997.tb00047.x

[4] Alvarez, K., Salas, E. and Garofano, C.M. (2004) An Integrated Model of Training Evaluation and Effectiveness. Human Resource Development Review, 3, 385-416. http://dx.doi.org/10.1177/1534484304270820

[5] Baldwin, T.T., Ford, J.K. and Blume, B.D. (2009) Transfer of Training 1988-2008: An Updated Review and Agenda for Future Research. International Review of Industrial and Organizational Psychology, 24, 41-70. http://dx.doi.org/10.1002/9780470745267.ch2

[6] Burke, L.A. and Hutchins, H.M. (2007) Training Transfer: An Integrative Literature Review. Human Resource Development Review, 6, 263-296. http://dx.doi.org/10.1177/1534484307303035

[7] Cheng, E.W.L. and Hampson, I. (2008) Transfer of Training: A Review and New Insights. International Journal of Management Reviews, 10, 327-341.

[8] Cheng, E.W.L. and Ho, D.C.K. (2001) A Review of Transfer of Training Studies in the Past Decade. Personnel Review, 30, 102-118.

[9] Brennan, J., Patel, K. and Tang, W. (2009) Diversity in the Student Learning Experience and Time Devoted to Study: A Comparative Analysis of the UK and European Evidence. Report to HEFCE, 21, Centre for Higher Education Research and Information, London, 7.

[10] Bandura, A. (1982) Self-Efficacy Mechanism in Human Agency. American Psychologist, 37, 122-147. http://dx.doi.org/10.1037/0003-066x.37.2.122

[11] Bandura, A. (1986) The Selectionist Paradigm and the Deconstruction of Agency Social Foundations of Thought and Action. Prentice-Hall, Englewood Cliffs.

[12] Bandura, A. and Locke, E.A. (2003) Negative Self-Efficacy and Goal Effects Revisited. Journal of Applied Psychology, 88, 87-99.

[13] Chen, C.M., Lee, H.M. and Chen, Y.H. (2005) Personalized E-Learning System Using Item Response Theory. Computers and Education, 44, 237-255. http://dx.doi.org/10.1016/j.compedu.2004.01.006

[14] Faerman, S.R. and Ban, C. (1993) Trainee Satisfaction and Training Impact: Issues in Training Evaluation. Public Productivity and Management Review, 16, 299-314. http://dx.doi.org/10.2307/3380872

[15] Kraiger, K., Ford, J.K. and Salas, E. (1993) Application of Cognitive, Skill-Based, and Affective Theories of Learning Outcomes to New Methods of Training Evaluation. Journal of Applied Psychology, 78, 311-328. http://dx.doi.org/10.1037/0021-9010.78.2.311

[16] Kirkpatrick, D.L. (1975) Evaluating Training Programs. Tata McGraw-Hill.

[17] Joreskog, K.G. and Sorbom, D. (1993) LISREL 8: Structural Equation Modelling with the SIMPLIS Command Language. Scientific Software.

[18] Kleinbaum, D.G., Kupper, L.L., Muller, K.E. and Nizam, A. (1998) The Method of Maximum Likelihood. Applied Regression Analysis and Other Multivariable Methods, 3, 639-655. Pacific Grove, Duxbury.

[19] Fornell, C. (1987) A Second Generation of Multivariate Analysis: Classification of Methods and Implications for Marketing Research. In: Houston, M.J., Ed., Review of Marketing, American Marketing Association, Chicago, 407450.

[20] Pajares, F. (1996) Self-Efficacy Beliefs and Mathematical Problem-Solving of Gifted Students. Contemporary Educational Psychology, 21, 325-344. http://dx.doi.org/10.1006/ceps.1996.0025 